\title{
TRANSLOCATION HETEROZYGOSITY AND SEX RATIO IN VISCUM FISCHERI
}

\author{
B. A. BARLOW \\ School of Biological Sciences, Flinders University, Adelaide, South Australia 5042 \\ and \\ D. WIENS \\ Department of Biology, University of Utah, Salt Lake City, Utah 84112
}

Received 3.xi.75

\begin{abstract}
Summary
Male plants of $V$. fischeri have $2 n=23$ and constantly produce seven bivalents and a multivalent chain of nine chromosomes at meiosis. Regular assortment results in transmission of 11 - and 12-chromosome genomes via the pollen. Female plants have the chromosome number $2 n=22$ and are homozygous for the 11-chromosome genome. The multivalent chain in the males is a consequence of reciprocal translocations, one of which was Robertsonian and one of which involved the chromosome carrying the sex determination factors. There is a constant female-predominant sex ratio of approximately $1: 2$ in $V$. fischeri, possibly maintained by gamete selection; the genes involved may have been linked with the sex determination mechanism through the translocation system.
\end{abstract}

\section{Introduction}

Viscum fischeri Engler is a mistletoe species apparently endemic to highland Kenya, where it has a relatively limited known distribution. It occurs sporadically on both sides of the Great Rift Valley between 1500 and 2250 m, and often forms local populations of unusually high density. The most common host is Croton megalocarpus Hutch., but it also parasitises at least 10 other species. Like many African Visca, V. fischeri is constantly dioecious, although dioecy is more common in the leafless species than in leafy ones like $V$. fischeri.

The unusual translocation heterozygosity in this species was previously described and illustrated by Wiens and Barlow (1973, 1975). Male plants were found to have a somatic chromosome number of $2 n=23$, and at first meiotic metaphase the chromosomes consistently associated as seven bivalents and an open multivalent chain of nine chromosomes. Regular alternate orientation and disjunction in the chain resulted in $4 / 5$ segregation, so that 11- and 12-chromosome genomes are transmitted via the pollen. The 11-chromosome set consisted of 10 metacentrics or submetacentrics and one acrocentric, while the 12-chromosome set had nine metacentrics or submetacentrics and three acrocentrics. Female plants had a somatic number of $2 n=22$ and produced 11 bivalents at meiosis, apparently being homozygous for the 11-chromosome set mentioned above. Viscum fischeri therefore is not a permanent translocation hybrid in the classical sense, such as Oenothera. In addition to the production of pollen with differing chromosome numbers and an odd-numbered translocation chain, $V$. fischeri also has 
an asymmetric karyotype, and (being dioecious) is an obligate outcrosser. None of these characteristics typifies presently known permanent translocation heterozygotes in other plant genera. The multivalent translocation chain which occurs in the male plants is functionally a sex multivalent, and the sex-determining system may be described as a multiple $\mathrm{X}$-multiple $\mathrm{Y}$ type $(5 \mathrm{Y} / 4 \mathrm{X})$; the male is the heterogametic sex.

In this paper further studies on the genetic system of $V$. fischeri are reported, and all data so far obtained are presented. Observations on sex ratio are reported and the possible origin and significance of the translocation system in $V$. fischeri are discussed.

\section{Materials AND Methods}

Flower buds and active shoot apices were fixed in ethyl alcohol/acetic acid $(3: 1)$ and stored in absolute ethyl alcohol at $-15^{\circ} \mathrm{C}$ whenever possible. Squash preparations of pollen mother cell meiosis and pollen grain mitosis were stained in aceto carmine. Pollen viability was estimated on the basis of staining reaction to acid fuchsin. Mitotic figures in female plants were obtained from actively growing shoot apices macerated and squashed in aceto orcein with 1 per cent $\mathrm{HCl}$ at $60^{\circ} \mathrm{C}$. For study of meiosis in female plants, young flower buds were first fixed in ethyl alcohol/acetic acid $(3: 1)$, embedded in paraffin, sectioned at $22 \mu$ and lightly stained in safranin. The location of the sporogenous tissue was thus determined (there are no discrete ovules in viscaceous mistletoes), and the size of the flower bud at the time of meiosis was established. A technique was then developed in which female flower buds of this size were fixed in ethyl alcohol/acetic acid $(3: 1)$, and a portion of the ovary about $0.3 \mathrm{~mm}$ long was dissected from the thick-walled differentiated cells, macerated as described above, squashed, and stained in aceto carmine.

The ratio of male to female plants was determined firstly from direct counts in the field. Plants were removed and individually identified, as autoparasitism and clumped distribution made accurate identification of individual plants otherwise difficult. Other methods of determining sex ratio were also attempted, including raising populations from seed to flowering, and karyotyping small embryos from mitotic squash preparations following pretreatment with saturated aqueous p-dichlorobenzene and fixation in ethyl alcohol/acetic acid (3:1). The latter techniques are better measures of sex ratio since they are less affected by differences in survival or longevity of male and female plants. They were abandoned, however, for reasons given below.

Voucher specimens have been deposited at the East African Herbarium (EA), University of Nairobi (NAI), State Herbarium of South Australia (AD) and Garrett Herbarium, University of Utah (UT).

\section{Observations}

\section{(i) Male plants}

The chromosome constitution and pairing behaviour of all male plants studied are summarised in table 1 and first meiotic metaphase and anaphase are illustrated in fig. 1. The collection localities represent virtually the entire known geographical range of the species, and since the regular, 


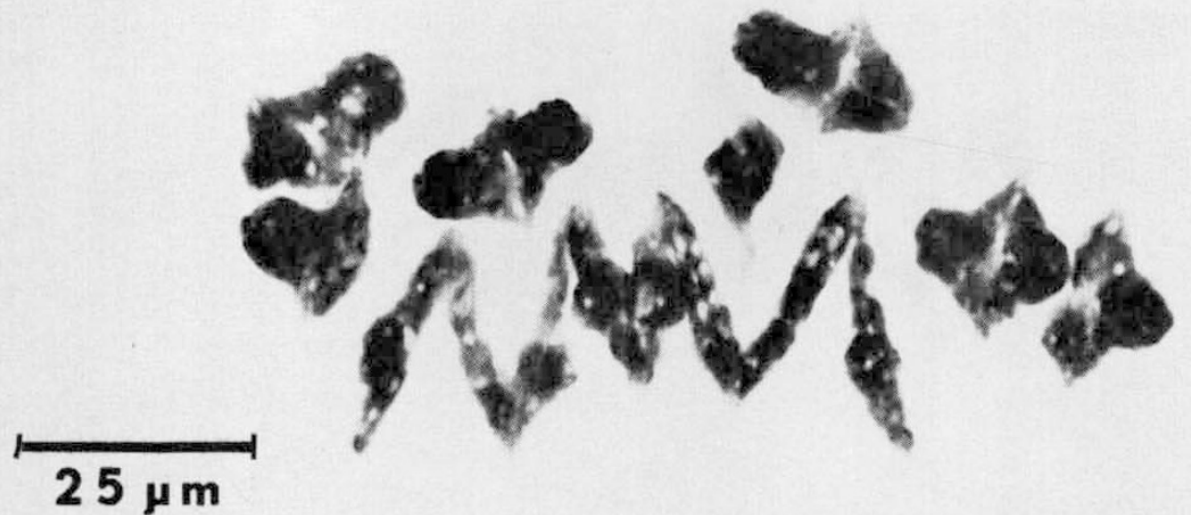

6
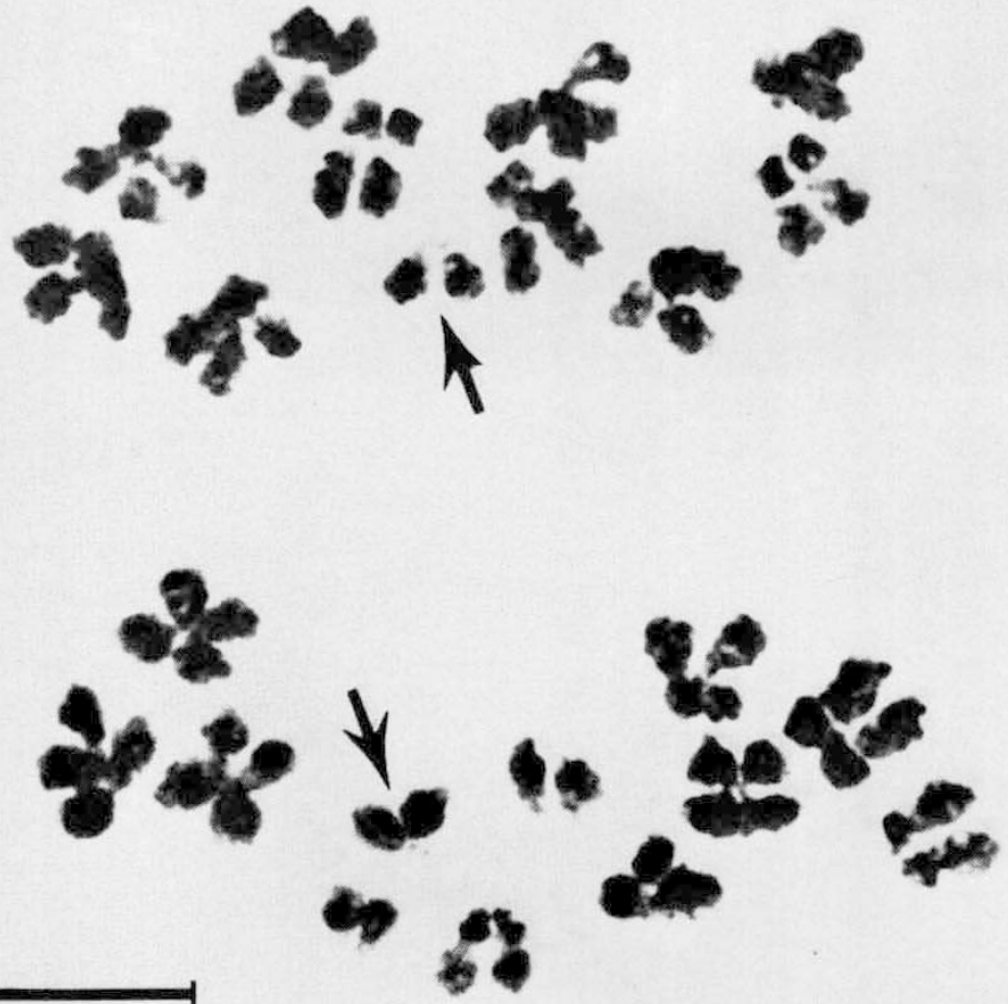

\section{$25 \mu \mathrm{m}$}

FIG. 1.-Meiosis in a PMC of $V$. fischeri. a, Metaphase I showing the chain of nine chromosomes and the seven bivalents. b, Anaphase I illustrating the 11- and 12-chromosome genomes resulting from the $4 / 5$ disjunction of the chromosome chain. Arrows indicate the single acrocentric chromosome in the upper 11-chromosome genome, and one of the three acrocentric chromosomes in the lower 12-chromosome genome. (Figure la, b, used by permission, see Acknowledgments.) 

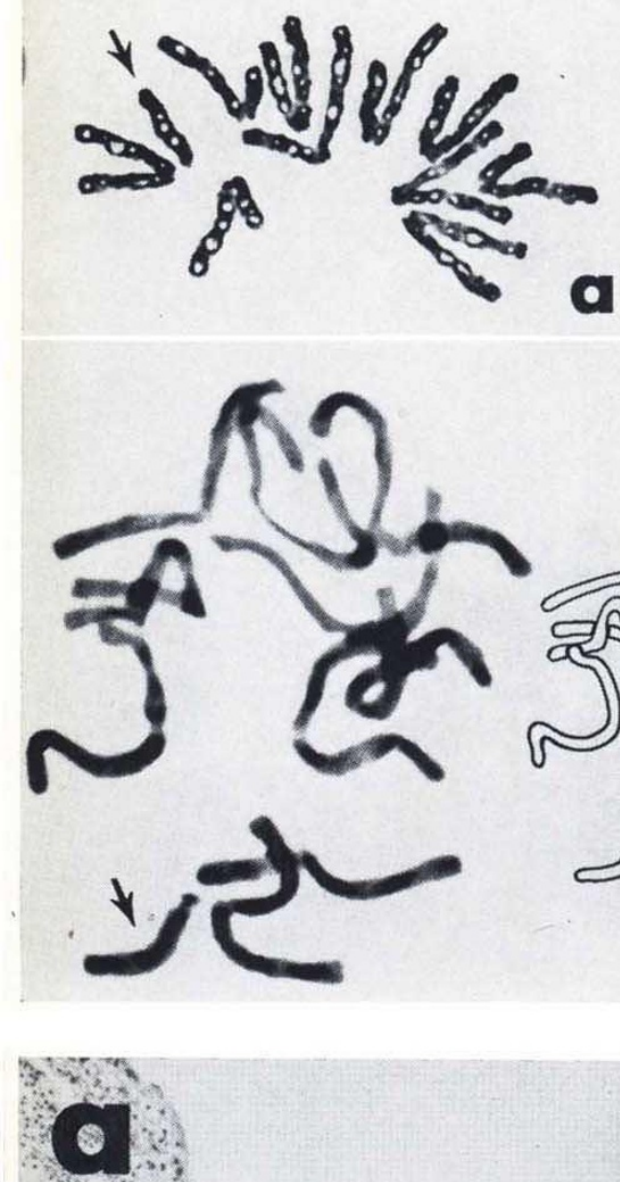

$4\left(\frac{1}{0.5 \mathrm{~mm}}\right.$

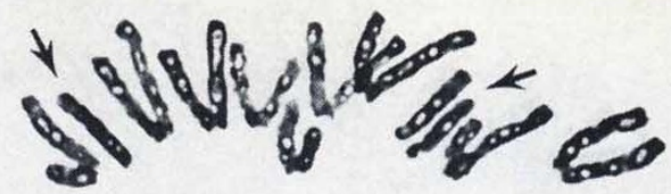

$25 \mu \mathrm{m}$

b

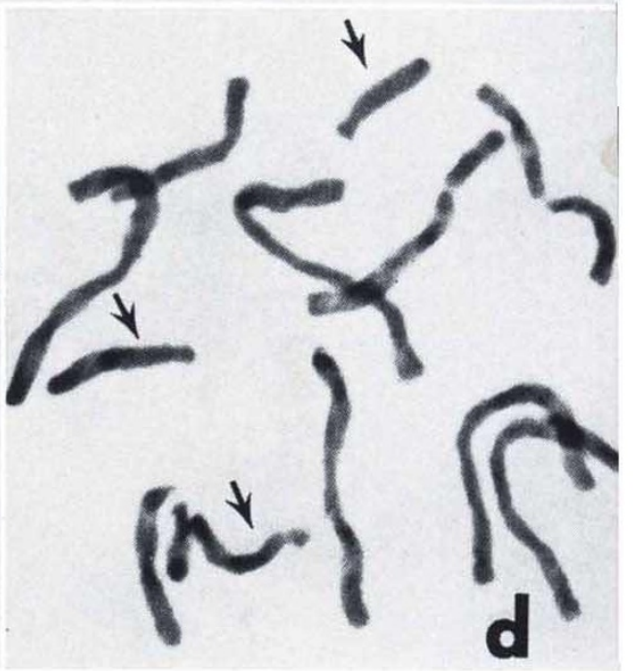


FIG. 2.-11- and 12-chromosome genomes of Viscum fischeri (arrows indicate acrocentric chromosomes). a, b, 11- and 12-chromosome genomes at second meiotic anaphase, respectively. c, d, 11- and 12-chromosome genomes at early metaphase of pollen grain mitosis, respectively. Scale on b also applicable to $\mathrm{a}, \mathrm{c}$ and $\mathrm{d}$.

FIG. 3.-Female flower of Viscum fischeri, showing sporogenous tissue (arrowed). a, L.S. of portion of inflorescence, showing flower at time of E.M.S.C. meiosis. b. Base of flower enlarged. 
alternate, orientation of the multivalent at metaphase I was confirmed in all materials examined the translocation heterozygosity in male plants therefore appears to be permanent. Precocious disjunction of the multivalent chromosomes was also constant ; they consistently separated before anaphase I movement commenced in the bivalents.

Pollen viability (stainability) was consistently over 85 per cent in the materials examined, and the spherical pollen grains comprised a single size class. Study of pollen grain mitosis in collection W4550 from Nairobi showed that both 11- and 12-chromosome genomes are present, at least to this stage of pollen development (fig. 2). Presumably all products of meiosis develop into normal pollen grains and both 11- and 12-chromosome genomes are transmitted through the male line.

\section{TABLE 1}

Male plants of Viscum fischeri used for study of chromosome constitution. (All plants had $7 I I$ and the chain of 9 chromosomes)

\section{Locality}

Nakuru Dist :

$2 \mathrm{~km} \mathrm{SE}$ of Turi, near Molo

Nakuru Dist:

$12 \mathrm{~km}$ NE of Lanet, near Nakuru

Nyeri Dist:

$\mathrm{N}$ boundary of Solio Game Reserve near Naro Moru

Nyeri Dist:

Near Naro Moru entrance gates, Mt. Kenya

Nat. Park

Nyeri Dist:

Kiganjo, $9 \mathrm{~km}$ E of Nyeri

Nyeri Dist:

$2-8 \mathrm{~km} \mathrm{~N}$ of Karatina

Nairobi:

Chiromo Campus, Univ. of Nairobi

Nairobi:

Ojiju and Taylor Streets, Nairobi

Nairobi:

National Museum grounds

Nairobi:

$0.5 \mathrm{~km} \mathrm{~W}$ of Karen on Ngong Road

$$
\begin{aligned}
& \text { Number of } \\
& \text { plants } \\
& \text { examined }
\end{aligned}
$$

$\begin{array}{llll}3 & \text { B2040 } & \text { B2041 } & \text { B2042 } \\ 2 & \text { B2045 } & \text { B2046 }\end{array}$

$1 \quad$ B2006

$1 \quad$ W4458

$2 \quad$ B2008 $\quad$ B2009

$9 \quad \mathrm{~B} 2010 \quad \mathrm{~B} 2011 \quad \mathrm{~B} 2012$

B2063 B2064 B2065

B2067 B2068 W4912

$8 \quad$ B2070 $\quad$ B2071 $\quad$ B2072

W4907 W4938 W4942

W4946 W4949

1 W4580A

$1 \quad \mathrm{~W} 4550$

$\begin{array}{llll}8 & \text { B2019 } & \text { B2027 } & \text { B2029 }\end{array}$

B2035 B2049 B2055

B2056 W4465

(ii) Female plants

The sectioned material of female flowers showed that there is a mass of about 15 embryo sac mother cells near the base of the ovary, which is solid in the early stages (fig. 3). Meiosis, which occurs when the bud is about half 
the length of the open flower, is possibly arrested at metaphase I for some time, as this stage was relatively easy to find. In several cases squash preparations were obtained which clearly showed a complement of 11 bivalents (fig. 4), unfortunately, clear photographs are technically difficult and have not so far been obtained. The results of the karyological work on female
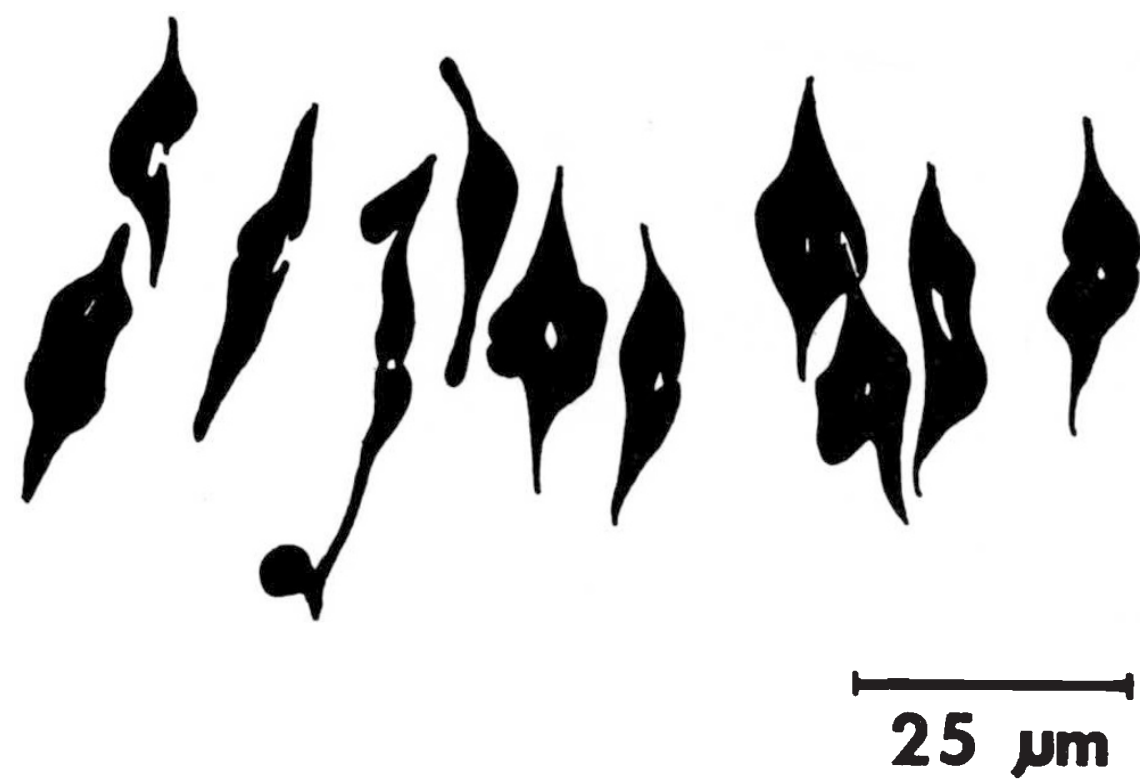

FIG. 4.-Meiotic metaphase I of an embryo sac mother cell in $V$. fischeri showing the $111 \mathrm{II}$. Camera lucida drawing.

plants, which also includes data based on mitotic studies from somatic tissues, are reported in table 2. These localities again represent an extensive survey of the geographic range of $V$. fischeri, and it is presumed that the female plants of the species are consistently structurally homozygous. Both meiotic and mitotic figures show that the genome in the female consists of 10 metacentric or submetacentric chromosomes and one acrocentric, and thus corresponds with the 11-chromosome set produced by the male.

Even though there is a massive sporogenous tissue in the ovary of $V$. fischeri, all dissections of young fruits have revealed only one endosperm mass and only one embryo. Occasional polyembryony, however, does occur in some viscaceous mistletoes.

\section{(iii) Karyotype}

An approximate karyotype is illustrated in Fig. 5. It was determined from analysis of anaphase II figures in the male (fig. 2a, b) supplemented by some measurements of mitotic metaphase chromosomes, and by visual study of the symmetry of the bivalents and multivalents in PMC meiosis. The seven bivalents of the male plants comprise three which are metacentric to slightly submetacentric (arm ratios from $1: 1$ to $1 \cdot 2: 1$ ), three which are more obviously submetacentric (arm ratios from $1 \cdot 4: 1$ to $2: 1$ ), 
and the small acrocentric. Of the nine chromosomes of the chain, the four which complete the 11-genome are composed of one which is approximately metacentric and three which are obviously submetacentric (arm ratios circa $1 \cdot 7: 1$ ). The five which complete the 12-genome consist of two which are approximately metacentric, one distinctly smaller submetacentric chromosome and the two small acrocentrics. The probable chromosome end sequence in the chain indicates that the pairing arms mostly differ considerably in length, and that translocations have occurred in at least six of the eight pairs of associating arms.

TABLE 2

Chromosome constitution in female plants of Viscum fischeri

Locality $\begin{gathered}\text { Number of } \\ \text { plants } \\ \text { examined }\end{gathered} \begin{gathered}\text { Chromosome } \\ \text { constitution }\end{gathered}$ Vouchers

Nakuru Dist:

$2 \mathrm{~km} \mathrm{SE}$ of Turi, near Molo

1

$$
\begin{gathered}
2 n=22 \quad \begin{array}{c}
\text { B2044 (parent for } \\
\text { embryo count) }
\end{array}
\end{gathered}
$$

Nyeri Dist:

$\mathrm{N}$ boundary of Solio Game Reserve near Naro Moru

Nyeri Dist:

$7 \mathrm{~km} \mathrm{~N}$ of Karatina

Nairobi:

Chiromo Campus, Univ. of Nairobi

Nairobi :

$1 \mathrm{~km} \mathrm{~W}$ of Karen on Ngong Road

$\begin{array}{ccl}1 & 11 \text { II } & \text { B2007 } \\ 4 & 11 \text { II } & \begin{array}{l}\text { B2060 } \\ \text { B2066 }\end{array} \\ 1 & 2 n=22 & \text { W4911 } \\ 1 & 11 \text { II } & \begin{array}{l}\text { B2059 } \\ \text { B2069 (parent for } \\ \text { embryo count) } \\ \text { W4909 }\end{array} \\ & 2 n=22 & \end{array}$

$\begin{array}{lllll}3 & 11 \mathrm{II} & \mathrm{B} 2100 & \mathrm{~B} 2101 & \text { B2102 }\end{array}$

\section{(iv) Sex ratio}

After field studies indicated that there could be a significant deviation from a sex ratio of $1: 1$ in favour of female plants, the methods described previously were adopted to measure sex ratio. The best method of determining sex ratio is through karyotypic analysis of embryos, since it eliminates the possibility of differential survival of adult plants. This method was abandoned, however, because a sufficiently high frequency of good mitotic figures could not be obtained. Response of the chromosomes to the contracting agent was negative (probably owing to the persistent layer of viscin around the isolated embryo). Only two embryos were clearly identified as to sex; both were female and the data are included in table 2.

Cultivating plants artificially to flowering has the disadvantage of the long time period needed to obtain a result in these woody plants. In a trial using 100 seeds, 80 were still attached to the host branches after 4 days, but only 45 were germinating after 12 days. After 6 weeks only a few of these seedlings showed signs of successful attachment. In Viscum album Showler (1974) determined that plants grown from seed required at least 4 years to flower, and that 26 per cent of plants had not flowered after 67 months. 

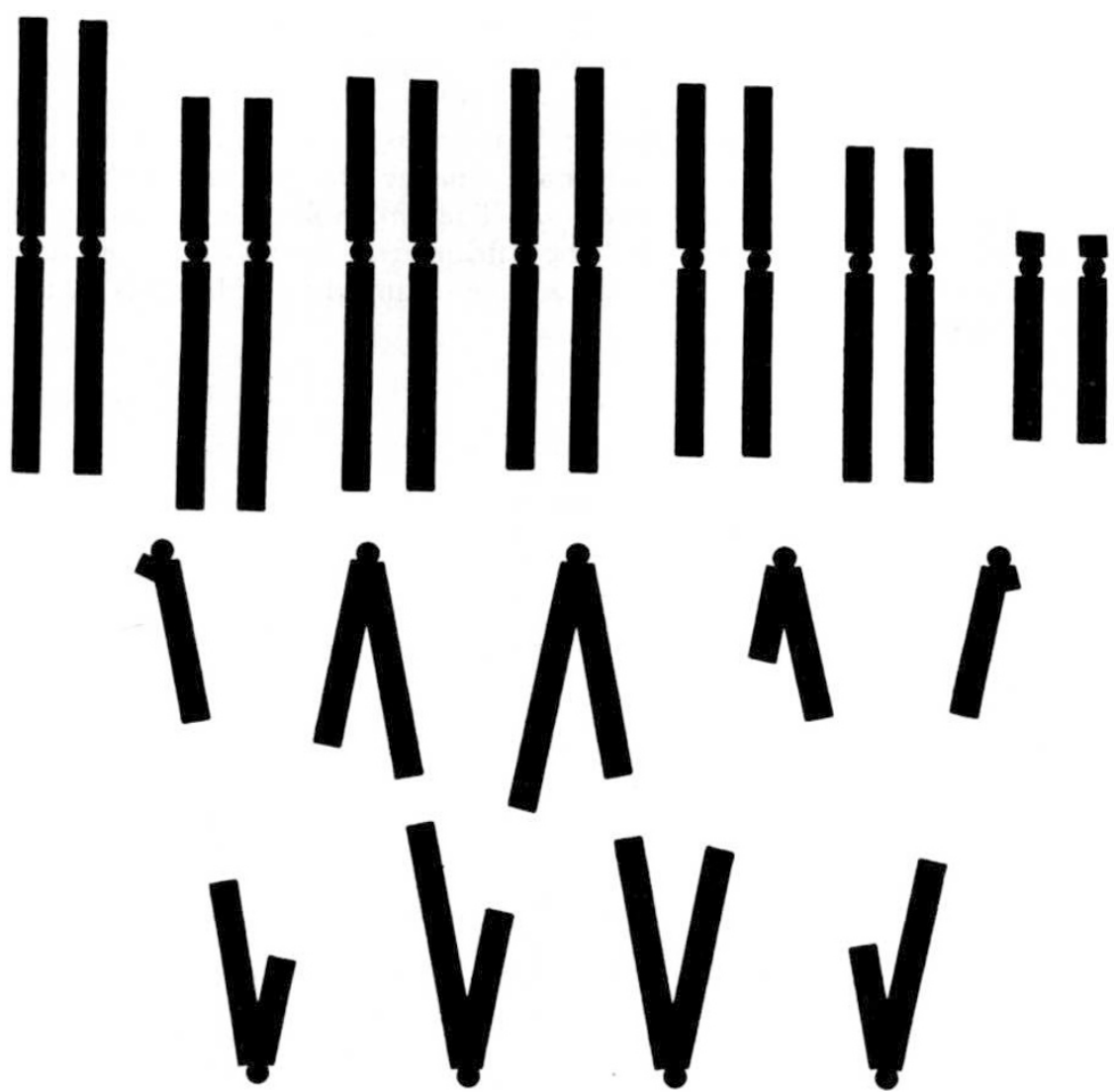

FIG. 5.-Karyotype of Viscum fischeri. Chromosomes which form the multivalent in the male are shown in probable pairing arrangement.

TABLE 3

Sex ratio in established populations of Viscum fischeri

Number of plants

Locality

Nyeri Dist:

$7 \mathrm{~km} \mathrm{~N}$ of Karatina

Nairobi:

Chiromo Campus, Univ. of Nairobi

Nairobi:

$0-5 \mathrm{~km}$ W of Karen on

Ngong Road

Total scored

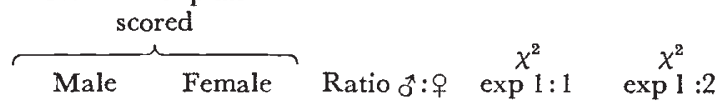

7

10

$0 \cdot 70$

0.53

0.45

23

42

$0 \cdot 55$

$5 \cdot 5 *$

$0 \cdot 12$

34

72

0.47

$13 \cdot 6 * *$

0.07

64

124

0.52

$19 \cdot 2 * *$

$* 0.02>\mathrm{P}>0.01$. ** $\mathrm{P}<0.001$. 
Sex ratio counts from established populations at three sites are set out in table 3. The pooled data show that the sex ratio differs significantly from $1: 1$ and in each separate population sampled there was a close fit to a $1: 2$ expectation. No heterogeneity in the samples is indicated $\left(\chi^{2}=5 \cdot 17\right.$, $0.8>\mathrm{P}>0.7)$; there is no reason for assuming that sex ratio varies significantly from one population to another.

\section{(v) Host specificity and habitat requirements}

Viscum fischeri is locally abundant around Nairobi and in some other areas, but is confined to mesic forests at middle elevations in the Kenyan highlands. It is most frequently parasitic on Croton megalocarpus but it was also sporadically observed on the following hosts: Acacia hockii De Wild., Croton macrostachyus Hochst., Diospyros abyssinica (Hiern) F. White, Heteromorpha trifoliata (Wendl.) Zeyh., Macaranga kilimandscharica Pax., Punica granatum L., Tapinanthus dschallensis (Engl.) Dans., T. kilimandscharicus (Engl.) Dans., Teclea simplicifolia Verdoorn and T. villosa M. R. F. Taylor. These are perhaps occasional hosts, and $V$. fischeri may have a relatively restricted habitat and host requirement, but precise data are not now available.

\section{Discussion}

(i) The stability of the translocation system in $\mathrm{V}$. fischeri

The translocation heterozygosity in $V$. fischeri is linked to sex determination, since it occurs only in male plants. Furthermore, the condition appears to be fixed in the species, since every male plant studied showed the same meiotic configuration of $7 \mathrm{II}$ and the chain of nine chromosomes, regular disjunction and apparently high pollen fertility. Similarly, every female plant studied carried two homologous sets of the 1l-chromosome genome. The chromosome system in $V$. fischeri is thus probably of relatively long establishment, and conserved by strong selection.

\section{(ii) Origin of the translocation system}

The translocation system has presumably been generated through a series of reciprocal translocations (Wiens and Barlow, 1973). Four translocations are necessary to explain the structural hybridity (fig. 6). One of these must have been Robertsonian, and one apparently involved the sex determination system, which we presume is simply inherited. Sex determination in plants is still poorly understood (Stebbins, 1971), but in the majority of cases where sex chromosomes cannot be identified visually, it is assumed that sex is determined by one gene locus or block of genes (Löve, 1957). Among dioecious angiosperm species in which the pattern of sex inheritance has been established, there is a preponderance of cases in which the male is the heterogametic sex (Lloyd, 1974a); this is also the case in $V$. fischeri, since the male is heterozygous with regard to the sex-linked translocations. Factors for femaleness and maleness are denoted by $\mathrm{X}$ and $\mathrm{Y}$, respectively, in the subsequent discussion and are taken as interacting in the classical sense.

Depending on the sequence in which the translocations occurred, there may or may not have been a transitional stage in which floating, closed rings 
of chromosomes were present. If the first translocation was the Robertsonian one, involving for example chromosomes $\mathrm{OP}$ and $\mathrm{QR}$ in the proposed model (fig. 6), then an open chain of three chromosomes would have been immediately generated, and the chain enlarged by subsequent translocations. Conversely, if translocations involving only metacentric chromosomes occurred before or contemporaneously with the Robertsonian one, then floating rings might have occurred prior to their incorporation in the chain. Similarly, the extent to which translocation heterozygosity has existed in female plants depends on the location of the sex determination factors, the relative timing
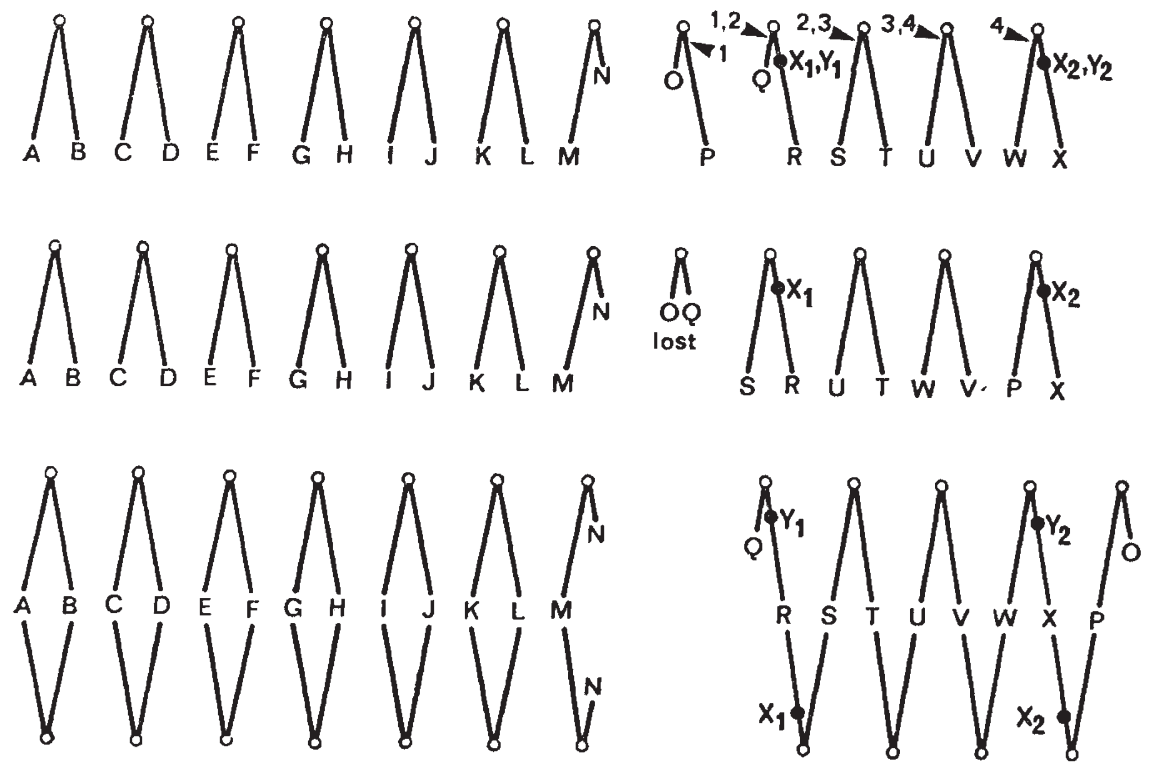

Fig. 6.-Suggested origin of the translocation complex in Viscum fischeri. Top row, original 12-genome; reciprocal translocations are numbered 1 to 4 ; translocation 1 is Robertsonian. Second row, derived 11-genome. Bottom, pairing pattern in male plant. See text for discussion of significance of possible sites $X_{1} / Y_{1}$ and $X_{2} / Y_{2}$ of sex determination factors.

of the translocation involving this factor, the location of subsequent translocations, and the time at which the translocated genome acquired a selective advantage (see below).

For example, if the first translocation was the Robertsonian one, and the sex determination factor was located on one of these acrocentric chromosomes (e.g. at site $\mathrm{X}_{1} / \mathrm{Y}_{1}$ in fig. 6 ), then the occurrence of structural heterozygosity in female plants may have been of short duration. That is, the evolution of sex-linked translocation heterozygosity may have proceeded almost entirely in male plants, with brief occurrences of floating translocation quadrivalents in the females, or even none at all. Conversely, if the translocation involving sex determination factors occurred late in the sequence, a large translocation complex may have occurred in both sexes before its eventual fixation in male plants only. If the sex determination factors were at a site such as $X_{1} / Y_{1}$ the floating complex would have been a closed ring; if the factors were at a site such as $\mathrm{X}_{2} / \mathrm{Y}_{2}$ (fig. 6) the floating complex would have been an open chain. 
Possibly the integrity of the growing translocation complex may have been better maintained during its evolution if it was fixed in the male through early linkage to a sex factor, attained an early selective advantage, and grew stepwise through incorporation of new translocations in the male line only. However, in other African species, i.e. V. hildebrandtii, plants with one, two or three translocation multivalents have been found (Barlow and Wiens, 1975), so that some of these are apparently not linked with sex and are floating in both male and female plants. However, studies of megasporogenesis to confirm this are incomplete.

The probable karyotype (fig. 5) shows that the pairing arms of the chromosomes of the translocation complex are generally unequal. Thus the majority of the translocations have presumably involved breaks in chromosome arms rather than centromeres, and the exchanges have usually been unequal. This may indicate that the postulated Robertsonian translocation involving the two acrocentric chromosomes has involved breaks near the centromeres rather than at them, as suggested for Gibasis by Jones (1974).

\section{(iii) Fixation of the translocation complex}

Since the derived translocation complex located in the 11-chromosome genome has reached the level of fixation as the only $\mathrm{X}$-carrying genome, it presumably has acquired a selective advantage over the postulated ancestral 12-chromosome genome. A simple model, using standard procedures for calculating genotype frequencies where selection is operating (Falconer, 1964), shows that any mutation conferring a selective advantage on plants carrying the translocation complex will lead to its fixation in homozygous females and heterozygous males. To take a simple example, assume that reciprocal translocation numbered 1 in fig. 6 has occurred, and that it involves the $\mathrm{X}$ factor which is located on chromosome arm $\mathrm{R}$. Then the genomes present in the population will be:

$$
\begin{aligned}
& \text { A.B C.D E.F G.H I.J K.L M.N* *O.P *Q.(Y)R S.T U.V W.X Genome I } \\
& \text { (ancestral) } \\
& \text { A.B G.D E.F G.H I.J K.L M.N* *O. } \downarrow \text { P } \quad{ }^{*} Q \downarrow \text {. (X)R S.T U.V W.X Genome II } \\
& \text { A.B G.D E.F G.H I.J K.L M.N* [*O.Q*] } \quad \text { P.(X)R S.T U.V W.X Genome III } \\
& \text { (derived) }
\end{aligned}
$$

* Short arm of acrocentric chromosome. $\quad \downarrow$ Sites of reciprocal translocation 1 .

and the possible types in the population will be:

$$
\begin{array}{cl}
\text { genomes } & \text { I + II -ancestral males (type A) } \\
\text { I + III - heterozygous translocated males (type B) } \\
\text { II + II - ancestral females (type C) } \\
\text { II + III-heterozygous translocated females (type D) } \\
\text { III + III-homozygous translocated females (type E). }
\end{array}
$$

If a mutation in the translocation complex confers a selective advantage when homozygous, i.e. female plants of type $\mathrm{E}$ have an advantage, then the type B males would obviously reach fixation along with the type $\mathrm{E}$ females. Similar trends would occur if a mutation confers an advantage on the translocated genome when heterozygous, or both heterozygous and homozygous, and effects fitness in male plants, or in both male and female. These trends 
are in fact similar to those which would occur in the case of simple selection for a mutation in a two-allele system.

Thus any favourable mutation in the translocation complex affecting fitness might have led to the permanent sex-linked translocation heterozygosity now present in $V$. fischeri. Such a mutation could have resulted in different fitnesses in male and female plants, and a distortion of the sex ratio, but it is perhaps unlikely that such a situation would have persisted in nature. If a male- or female-predominant sex ratio did not confer any selective advantage on the population, then selection might have strongly favoured a new translocation which would uncouple the favourable mutation from the sex determination system, resulting in equal expression in both sexes.

\section{(iv) The significance of the sex ratio}

The distorted sex ratio in $V$. fischeri might, therefore, be a consequence of higher fitness of female plants. Lloyd (1974a) has calculated that under such conditions equilibrium would, in fact, be reached with an excess of female plants in the population. In such a situation, however, the sex ratio at zygote formation should be normal and the distortion appear only during subsequent development. Unfortunately, adequate data on sex ratios in embryo and seedling populations have not yet been obtained. If, however, the sex ratio is a latent developmental phenomenon, it might be more variable from site to site, and since there are alternative explanations of deviations from a sex ratio of unity, the significance of the sex ratio requires further consideration.

A female-predominant sex ratio could be of benefit to a dioecious plant species, since (given an adequate pollination mechanism) the reproductive potential would be increased. This should be highly advantageous to a colonising species (or $r$ strategist) such as $V$. fischeri and many other mistletoes. These species have virtually no interspecific competition, high host specificity, high seed and seedling mortality, and generally highly unpredictable reproductive success. Several workers have, in fact, suggested that the adaptive significance of female-predominant sex ratios in angiosperms is that it maximises seed production (Lewis, 1942; Mulcahy, 1967; Kaplan, 1972). However, Lloyd $(1974 a, b)$ has questioned the idea.

The distorted sex ratio in $V$. fischeri may therefore not be produced by mutation in a translocation complex affecting fitness. Rather, it may be causal in the sense that the translocation heterozygosity is simply a mechanism to maintain the integrity of a genetic system producing gamete selection and concomitant sex ratio distortion. For example, a mutation linked to $\mathrm{X}$ might produce faster pollen germination and/or pollen tube growth and thus a higher frequency of successful fertilisations, as demonstrated in Silene alba (Correns, 1928).

Although there is a massive sporogenous tissue in the ovary of $V$. fischeri, only a single embryo and endosperm mass have been observed. As mentioned previously, there are no true ovules in Viscaceae and in $V$. fischeri about 15 embryo sac mother cells develop at the base of the ovary. At least two embryo sacs normally develop in Viscum. These grow upward toward the style where fertilisation takes place. If more than one embryo is fertilised, then competition necessarily occurs between the proembryos because only the first to reach the base of the ovary will ultimately develop into a mature 
embryo and endosperm. Thus, as Kuijt (1969) has pointed out, the embryo sacs to varying degrees assume the function of a pollen tube and a similar competitive situation is created. Hence, gamete competition could conceivably take place in both pollen tubes and embryo sac and strong selective pressure exerted for efficient pollen tube and/or embryo sac and endosperm development. This entire area, however, needs further study.

If random mating and constant population size are assumed, and no other directional selection is operating, the trends are similar to those described above, except that a distorted sex ratio is produced in which the ratio of a female to male plants is equal to the relative efficiency of the translocated X-carrying pollen. In other words, a gamete performance mutant located in the translocation complex can lead to fixation of the translocation complex in male and female plants and permanent distortion of the sex ratio, even in the absence of any mutants affecting relative fitness of male or female plants. This conclusion agrees with the more general one of Lloyd (1974a) that differential fertilisation in dioecious plant species is correlated with sex ratio. Frequencies of the genotypes were calculated for 22 generations with the initial frequency of the Robertsonian translocation set for convenience at 0.2 and the relative efficiency of the translocated X-carrying pollen set at $1 \cdot 5$. This latter figure is lower than the figure of 1.94 which can be inferred from the actual data. After about 20 generations the frequencies of ancestral and translocated types were reversed.

Among the known examples of female-predominant sex ratios in dioecious angiosperms, the ratios have been explained primarily in terms of gamete selection (cf. Lloyd, 1974a, b). In four of the eight genera reviewed by Lloyd, there is some experimental evidence that this is in fact the case. The suggested genetic basis of the sex ratio in $V$. fischeri therefore conforms with systems suggested for other groups. If there is in fact a gamete selection factor involved in the genetic system of $V$. fischeri, and if the translocations have any relevance in the system, then the gamete selection factor must have occurred on a chromosome not originally carrying the $\mathrm{X}$-factor, and must have arisen after a fortuitous translocation linked the locus to $\mathrm{X}$. Otherwise the factor would have occurred in all five types in the population and a distortion of the sex ratio would not have occurred.

$A$ recent study of germination and development in the European mistletoe, $V$. album, shows that a female-biased sex ratio of approximately $1: 2$ also occurs in this species (Showler, 1974). There are no reports of translocation heterozygosity in this species, but apparently there have been no meiotic studies made since those of Pisek (1923) and Steindl (1935), who utilised sectioned material in their analysis. A single photograph of first meiotic metaphase by Pisek shows what appears to be two overlapping bivalents. This might, however, be a ring of four chromosomes which are sometimes difficult to distinguish from two overlapping bivalents. The meiotic pairing relationships of this species needs further examination.

\section{(v) The translocation complex and the differentiation of sex chromosomes}

As we have pointed out earlier (Wiens and Barlow, 1975), the nine chromosomes comprising the multivalent in the male cannot be regarded as sex chromosomes in the strict sense. In other species of Viscum studied karyologically, there are no indications of identifiable sex chromosomes 
(Wiens and Barlow, 1971; Wiens, 1976). Sex is probably determined in a genetically simple fashion, as mentioned earlier. Most components of the multivalent are presumably autosomes brought into the sex-determining system fortuitously through reciprocal translocations. Viscum fischeri technically has a $\mathrm{X}_{1} \mathrm{X}_{2} \mathrm{X}_{3} \mathrm{X}_{4} / \mathrm{Y}_{1} \mathrm{Y}_{2} \mathrm{Y}_{3} \mathrm{Y}_{4} \mathrm{Y}_{5}$ sex-determining system. This considerably exceeds in complexity any other recorded for plants (Ono, 1937), and is exceeded by only one system in animals (Guénin, 1953) and equalled by another (Ogawa, 1954). As we indicated earlier (Wiens and Barlow, 1975) and as White (1973) had already pointed out, these highly complex chromosome systems do not " make sense " when viewed simply as mechanisms of sex determination. Neither do we believe they "make sense" when viewed in terms of permanent hybridity (as in Oenothera), since at least in $V$. fischeri heterozygosity is limited to males. Furthermore, it is the females (which are structurally homozygous) that presumably have achieved higher fitness through the distorted sex ratio. Thus we believe that the best explanation for the extraordinary translocation heterozygosity in $V$. fischeri is that it maintains the integrity of highly adaptive gene complexes.

These observations provide little support for the argument by Lloyd (1974b) that the "sex chromosome differentiation hypothesis" may be a better explanation of female-predominant sex ratios than the "maximum seed set hypothesis". According to the former, if the multivalent in $V$. fischeri is presumed to be a differentiated sex chromosome complex, then it can be argued that accumulation of non-functional genes in the Y complex may affect both sporophyte and gametophyte generations, so that pollen grains carrying the $\mathrm{Y}$ chromosome complement are at a competitive disadvantage. As Lloyd points out, however, the evidence for genetic inertness of $\mathrm{Y}$ chromosomes in dioecious angiosperms is rather inconsistent, and in $V$. fischeri there is no evidence of such inertness.

The other arguments against the "maximum seed set hypothesis" concern (1) how group selection can maintain biased sex ratios, (2) how biased sex ratios can vary in relation to environmental conditions and (3) the rarity of biased sex ratios in dioecious angiosperms. The rarity of biased sex ratios probably reflects the rarity of environmental and genetic situations which favour maximising seed set in dioecious angiosperms in this way. In our opinion, $V$. fischeri may be a case in which habitat stability, interspecific interactions, and the nature of the reproductive system favour a constant female-predominant sex ratio. The way in which the ratio has been established, through translocation-generated linkage to the sex determination system of factors for gamete selection, is perhaps clear, and it may be necessary to argue that some form of group selection has maintained the biased ratio. This aspect is being further considered.

\section{(vi) Enlargement of the multivalent chain}

In the model presented a relatively small translocation complex could generate the system found in $V$. fischeri. The basic requirement is a translocation linking a gamete performance factor to the $\mathrm{X}$ site of the sex determination system. This situation may exist, for example, in Rumex hastatulus, where a female-biased sex ratio is associated with the occurrence of a sex trivalent (Smith, 1963).

Why, then, is the translocation complex in $V$. fischeri so large? Since the 
chain of 9 is fixed throughout the species, it is presumably conserved by natural selection. The postulated gamete performance mutant might only have been linked with the $\mathrm{X}$ factor through a fortuitous sequence of earlier translocations. This seems unlikely, however, because subsequent changes in chromosome end sequence could reduce the complex and bring the factors into closer linkage (cf. James, 1970). It is more likely that the genetic linkage groups of 5 and 4 chromosomes in the complex each have intrinsic adaptive value.

Some of the reasons why the complex might have reached its present size are classical. Just as in Oenothera, Rhoeo, and Isotoma, it can be suggested that a large ring is mechanically more likely to achieve correct orientation and assortment than a smaller one (Stebbins, 1950). More specifically, however, it could be argued that genes which are concerned with the structure and regular behaviour of the multivalent are likely to become located in the multivalent itself. Assuming that such processes as the regular (zig-zag) orientation of the chain and the precocious anaphase separation of the multivalent chromosomes are specifically controlled genetically, selection may have favoured any translocation which linked these genes to the complex. Similarly, other factors affecting the ecological situation in $V$. fischeri might have been incorporated later into the complex by enlargement. These could include, for example, modifying factors for sex ratio which might keep the population near an optimal balance between males and females, and factors which might have specific adaptive value in male or female plants.

\section{(vii) Uniqueness of the $\mathrm{V}$. fischeri system}

Translocation heterozygosity is of widespread occurrence in dioecious African Visca (Wiens and Barlow, 1975; Barlow and Wiens, 1975; Wiens, 1976 and unpublished data), but none is known in monoecious species. Data for many species are severely limited, but of the 21 dioecious African Visca for which chromosome numbers are now known (Wiens, 1976), 11, or 57 per cent, exhibit translocation heterozygosity. Of the remaining 10 , five appeared to have no translocations and for the remaining five insufficient material was available to determine meiotic pairing relationships. Thus translocation heterozygosity is apparently an important feature of evolution in African Visca. We estimate there are perhaps 35-40 species of dioecious Visca in Africa and a total of approximately 65 species. Our recent collections contain about 30 to 40 per cent of undescribed species. No information is presently available on possible translocation heterozygosity in the large Madagascan and Asian elements of the genus. The entire problem, however, is being further investigated.

All the species so far studied, except $V$. fischeri, have translocation multivalents with closed associations forming rings of four, six, or eight chromosomes. In $V$. hildebrandtii plants are known with one, two, and three separate translocation rings of varying complexity (Barlow and Wiens, 1975). Nothing, however, approaches the unique, sex-determining chain multivalent known in $V$. fischeri. Furthermore, the female-predominant sex ratio observed in $V$. fischeri is also presently unknown in other species, but little data on this aspect is yet available. Therefore, while translocation heterozygosity may be a characteristic feature of many dioecious African Visca, the 
nature of the translocation complex and its adaptive role in $V$. fischeri is perhaps uniquely different from other species of the genus.

Acknowledgments. - We thank especially Dr J. O. Kokwaro of the University of Nairobi, and the staff of East African Herbarium, Nairobi, particularly Mr J. B. Gillett. Both institutions provided facilities and other assistance. The research was partially supported by the Australian Research Grants Committee, the Flinders University Research Committee, and U.S. National Science Foundation Grant (GB 27273). Fig. la is used by permission of Science where it was published previously by D. Wiens and B. A. Barlow, Vol. 187, pp. 12081209, 28th March 1975, copyright 1975 by American Association for the Advancement of Science. Fig. $1 \mathrm{~b}$ is used by permission of Nature New Biology where it was published previously by D. Wiens and B. A. Barlow, Vol. 243, no. 124, pp. 93-94, 16th May 1973.

\section{REFERENCES}

BARLOW, B. A., AND WIENS, D. 1975. Permanent translocation heterozygosity in Viscum hildebrandtii Engl. and V. engleri Tiegh. In East Africa. Chromosoma, 53, 265-272.

CORRENs, c. 1928. Bestimmung, Vererbung und Verteilung des Geschlechtes bei den hoheren Pflanzen. Handb. Vererbungsw., 2, 1-138.

FALCONER, D. S. 1964. Introduction to Quantitative Genetics. Oliver and Boyd, Edinburgh.

GUÉNIN, H. A. 1953. Les chromosomes sexuels multiples de Blaps polychresta Forst. (Col. Tenebr.). Rev. Suisse Zool., 60, 462-466.

JAmes, s. H. 1970. Complex hybridity in Isotoma petraea. II. Components and operation of a possible evolutionary mechanism. Heredity, 25, 53-77.

JONES, K. 1974. Chromosome evolution by Robertsonian translocation in Gibasis (Commelinaceae). Chromosoma, 45, 353-368.

KAPLAN, s. m. 1972. Seed production and sex ratio in anemophilous plants. Heredity, 28, 281-285.

kuijt, J. 1969. The Biology of Parasitic Plants. Univ. of California Press, Berkeley and Los Angeles.

LEWIS, D. 1942. The evolution of sex in flowering plants. Cambr. Phil. Soc. Biol. Rev., 17, 46-47.

LLOXD, D. G. 1974a. Theoretical sex ratios of dioecious and gynodioecious angiosperms. Heredity, 32, 11-34.

LLOXD, D. G. 1974b. Female-predominant sex ratios in angiosperms. Heredity, 32, 35-44.

Löve, 1957. Sex determination in Rumex. Proc. Genet. Soc. Canada, 2, 31-36.

мULCAHх, D. L. 1967. Optimal sex ratio in Silene alba. Heredity, 22, 411-423.

OGAWA, K. 1954. Chromosome studies in the Myriapoda. VII. A chain-association of the multiple sex chromosomes found in Octocrytops sexspinosus (Say). Cytologia, 19, 265-272.

ono, т. 1937. On sex-chromosomes in wild hops. Bot. Mag. (Tokyo), 51, 110-115.

PISEK, A. 1923. Chromosomenverhältnisse, Redukionsteilung und Revision der Keimentwicklung der Mistel (Viscum album). Jahrb. f. Wiss. Bot., 62, 1-19.

sHowler, K. 1974. Raising mistletoe (Viscum album) from seed. 7. Roy Hort. Soc., 99, 30-37. sмгтн, в. w. 1963. The mechanism of sex determination in Rumex hastatulus. Genetics, 48, $1265-1288$.

stebBins, G. L. 1950. Variation and Evolution in Plants. Columbia Univ. Press, New York.

stebbins, G. L. 1971. Chromosomal Evolution in Higher Plants. Edward Arnold, London.

STEINDL, F. 1935. Pollen und Embryosackentwicklung bei Viscum album L. und Viscum articulatum Burm. Schweiz. Bot. Gesell. Ber., 44, 343-388.

white, M. J. D. 1973. Animal Cytology and Evolution. Cambridge Univ. Press, 3rd edition. wIENs, D. 1976. Chromosome numbers in African and Madagascan Loranthaceae and Viscaceae. 7. Linn. Soc. (Bot.) (in press).

WIENS, D., AND BARLOW, B. A. 1971. The cytogeography and relationships of the viscaceous and eremolepidaceous mistletoes. Taxon, 20,313-332.

WIENS, D., AND BARLOW, B. A. 1973. Usual translocation heterozygosity in an East African mistletoe (Viscum fischeri). Nature New Biol., 243, 93-94.

WIENS, D., AND BARLOW, B. A. 1975. Permanent translocation heterozygosity and sex determination in East African mistletoes. Science, 187, 1208-1209. 